\title{
Analysis of The Demand for Older Adult Care Services and Related Influencing Factors Among Older Adults Living Alone in China
}

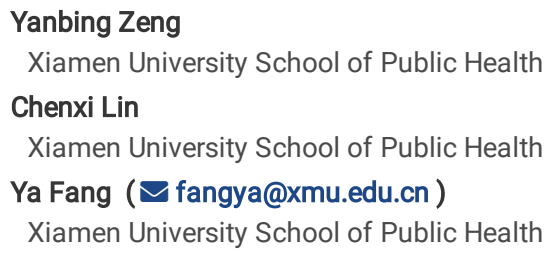

Research article

Keywords: Living arrangements, Home and community-based care, Aging at place, Regression methods

Posted Date: November 13th, 2020

DOI: https://doi.org/10.21203/rs.3.rs-104522/v1

License: () (i) This work is licensed under a Creative Commons Attribution 4.0 International License. Read Full License 


\section{Abstract}

Background: The number of older adults living alone in China is rising sharply and their care needs have become an increasing public health concern. This study aimed to explore the anticipated living arrangements and demand for home and community-based care services (HCBS) of older adults living alone and examine the related influencing factors.

Methods: The data of 2217 participants living alone were extracted from the 2018 Chinese Longitudinal Health Longevity Survey (CLHLS). A chi-square test was used to examine the differences in older adult care services between respondents with different characteristics. Using the Andersen model as the analysis framework, multinomial and binary logistic regressions were used to analyze the influencing factors of anticipated living arrangements and HCBS, respectively.

Results: $75.4 \%$ of the respondents hoped to maintain living alone when considering the future. Those who were older, had more children, income source was family members, always felt lonely and isolated and had limitation in activities of daily living (ADL) were inclined to choose the arrangement of "co-residence with children". Childless and loneliness had significant impact on older adults' willingness to live in institution. There were significant differences between urban and rural areas for provision of HCBS and the demand exceeds supply in all service types. Those who were younger, lived in urban areas, farmers, income source was family members, had poor economic status, had access to social services, with higher sense of loneliness and chronic diseases tend to show anticipated demands for various HCBS.

Conclusions: The demand for older adult care services were affected by predisposing, enabling and need variables. There is a need for an overall improvement of the community care system to create a supportive environment for older adults living alone.

\section{Background}

Population aging is a major social problem around the world, especially in China, the most populous country[1]. Statistics show that there were over 230 million older adults in China in 2017, which accounted for $16.2 \%$ of the total population. It is estimated that the proportion of older adults will exceed $30 \%$ by 2050[2]. With the aging trend of the population, living arrangements have become one of the most pressing concerns. As the result of the one-child policy, rapid socioeconomic transformation, and lifestyle changes, the traditional living situation of co-residing with family has been challenged. First, the population age structure was reshapred as a result of of dramatic decline in both fertility and mortality, the household size is decresing. Second, due to the process of urbanization, apartments containing small units suitable only for nuclear families become a more general form of housing[3]. Last but not least, it has been a trend that numberous of young generation moved into cities for better job opputinities as a result of income inequality between regions and the policies that have stimulated labour mobility[4]. Under the circumstance, the living arrangements of older adults has changed, the number of older adults living alone has soared in China, which was approximately 23 million in 2016, rising to 25 million in 2020 [5]. The surge in number of older people, many who live alone, has posed great challenges to our economy and society, especially within the older adult care system.

Older adults living alone have been regarded as an "at risk" group by the World Health Organization[6]. A growing body of research has demonstrated that older adults living alone face a series of problems that merit attention. Several studies pointed out that older adults living alone had worse psychological health $[3,7,8]$, were more likely to be depressed $[9,10]$, reported higher levels of loneliness, and received less social support compared with those who were not living alone[11]. Furthermore, numerous studies have revealed that living alone has a negative effect on the quality of life (QoL) and life satisfaction of older adults[1, 12]. However, results from different studies regarding health status of older adults living alone are not consistent. A study from the United States reported that older adults living alone have health advantages [13], while another study from the United Kingdom found no association between living alone and physical health status[14]. There are also studies that have suggested that those living alone seem to have better functionality and self-rated health [15, 16]. Surveys conducted in China have indicated that the percentage of Chinese older adults living alone is higher amongst the oldest old (80 years and older) [17] and a large number of older adults living alone are without a dedicated caregiver in the household[18].

To address the serious care problem of older adults, especially those who live alone, home and community-based care services (HCBS) has been advocated by the Chinese government and plays an increasingly significant role in care provisions. It is a new nursing mode that is family-cored, community-based and rely on the professional services. HCBS encompasses a broad range of services and support, including daily care, domestic services, medical and nursing services, psychological services, and so on[19], which helps older adults remain in their homes and assist in maintaining a decent QoL in familiar settings. However, with a growing demand for different types of older adult care services, there are insufficient provisions to respond to the surge in demand, which have been the main barrier to the development of the older adult care system. Under the current circumstances, focusing on the care needs of older adults living alone in China is extremely important. Understanding the demand for older adult care services will enable the implementation of appropriate incentive schemes to promote the utilization of HCBS among people living alone, and allow them to lead independent and healthy lives[20].

To our knowledge, most studies that refer to older adults living alone were about health-related quality, depressive symptoms, psychological well-being, and utilization of health services [12,21-24]. There is paucity of research investigating the demand of older adult care needs and influencing factors of those living alone. Therefore, we aimed to explore the anticipated living arrangements and demand for HCBS among older adults living alone, identify the associated influencing factors to have a better understanding of this group, and ultimately develop appropriate health and social services for older adults to help cope with the challenges of an aging population.

\section{Methods}

\section{Study sample}


We analyzed data from the 2018 Chinese Longitudinal Healthy Longevity Survey (CLHLS), which was conducted by the Healthy Ageing and Development Research Center at Peking University. The CLHLS was a high-quality, nationally representative survey of Chinese residents aged 65 years and older, collected by face-to-face interviews in respondents' homes. It provided a rich set of information on demographic and socioeconomic characteristics, physical and psychological function, health-related behaviors and lifestyles, and health care. In addition, information on the care needs of older adults living alone was collected. A detailed description of the study design, sample distribution and content of the data collected from CLHLS is available in Zeng et al[25]. (The questionnaire used in this study has previously been published in https://www.icpsr.umich.edu/web/DSDR/studies/.)

We focused on older adults who were aged 65 years and over and lived alone at the time of the interview. For the purpose of this study, participants who were under 65 years old, institutionalized, had incomplete residential information, or lived with spouses or others were excluded. A total of 2217 participants were analyzed (Table 1).

\section{Andersen Theoretical Model}

To intergrate the factors that may have an impact on the demand for older adult care services, we adopted Andersen's Behavioral Model [26] as the analytical framework. The Andersen model divides the use of health services into predisposing characteristics (including demographic characteristics such as ethnicity, age, sex), enabling resources (range from family to environmental level variables such as houshold income and social support network), and need factors (focusing on the functional dependency of the care recipient such as health status and activities of daily living[ADL]). It was originally proposed in 1960s aimed to describe and predict the utilization of medical services. Nowadays, it has been also widely used in studies relating to the need and use of long-term care services among older adults [27-29]. In this study, the Andersen model was used to analyze the associations between predisposing, enabling, and need variables with the need for different older adult care services.

\section{Dependent Variables}

In this study, older adult care needs included two dimensions: anticipated living arrangements and anticipated home and community-based care services. In the CLHLS questionnaire, "What is your anticipated living arrangements" was used to measure anticipated living arrangements of older adults living alone. There were five response options: (1) living alone regardless of residential distance from children; (2) living alone and children living nearby; (3) co-residence with children; (4) institution (older adult center or home); or (5) do not know.

Anticipated HCBS of older adults were measured by the question "Which kind of home and community-based care services do you need". Response choices were as follows: (1) personal daily care services; (2) home visits; (3) psychological consulting; (4)daily shopping; (5)social and recreation activities; (6)legal aids; (7)health education; (8)neighboring relations; and (9)other.

\section{Independent Variables}

Independent variables were categorized as predisposing, enabling, and need characteristics. Predisposing factors included age (65-74, 75-84, $\geq 85$ years), sex (male or female), residence (rural or urban), years of schooling $(0,1-6, \geq 7$ years) and occupation (farmer or non-farmer).

Enabling resources included number of children $(0,1-3, \geq 4)$, primary caregiver (son, other relatives, friends, or nobody), economic status (high, intermediate, or low), income source (self, family members, or others), availability of home visits in the community (no or yes), availability of personal care services in the community (no or yes).

Need variables were expressed by the frequency of feeling lonely and isolated (never, sometimes, or always), self-rated health (good, fair, or bad), ADL (not limited or limited), have chronic diseases (no or yes).

\section{Data analysis}

Data were analyzed using SPSS for Windows version 22.0 (SPSS Inc., Chicago, IL, USA). Predisposing, enabling, and need variables were expressed as percentages and frequencies. A chi-square test was used to examine the differences in older adults care services between respondents with different characteristics. Multinomial logistic regression was used to analyze the influencing factors of living arrangements and binary logistic regression was used to analyze the influencing factors of the need for all types of HCBS among older adults living alone, from the three aspects of predisposing, enabling, and need factors. A value of $p<0.05$ was considered statistically significant.

\section{Results}

\section{Sample characteristics}

A total of 2217 respondents were included in our study. Table 1 describes the sample. $53.3 \%$ were aged over $85,63.9 \%$ were female, $50.7 \%$ lived in urban areas, $69.5 \%$ were engaged in farming, and $57.7 \%$ had never attended school.

In terms of enabling resources, $92.6 \%$ of the elderly were widowed. $63.9 \%$ of the elderly had more than 3 children. $70.7 \%$ reported that their economic status were similar to that of their neighbors. $48.8 \%$ of older adult's income source were family members. $49.1 \%$ of the elderly reported that their primary caregiver were their son when they got sick. 
In addition, $32.0 \%$ of participants were limited in ADL by health problems. A majority of the sample reported good or fair health status. However, almost $70 \%$ had at least one chronic illness. On the psychological level, $45.9 \%$ of the sample felt lonely and isolated.

\section{Anticipated future living arrangements}

Table 2 depicts the anticipated future living arrangements of older adults. Among the 2217 respondents, the combined percentage of older adults who wanted to live alone was $75.4 \%$. However, there were some differences in the patterns of living alone, which was mainly reflected in the distance to their children's home. In both urban and rural areas, almost half of older adult respondents preferred to continue living alone in the future over any other living arrangement, but hoped their children live nearby. Around one fifth of respondents reported that they would prefer to live alone regardless of the residential distance from their children. Co-residing with children was preferred by $17.2 \%$ respondents. Very few people (less than $3 \%$ ) reported that they would prefer to live in institution, such as older adult centers and homes. The chi-square test showed significant differences of anticipated living arrangements in older adults in age, sex, years of schooling, number of children, economic status, income source, primary cagariver, loneliness, self-rated health and ADL ( $p<0.05)$.

\section{Anticipation and availability of HCBS}

Table 3 presents the demand and supply of HCBS. Among all types of services, the category of health care services, such as home visits and health education were in most demand, accounting for $81.73 \%$ and $73.63 \%$ of respondents, respectively. Other services were also in high demand with over $60 \%$ of respondents reporting a need for all services. Compared with demands, we found that the supply of services was highly inadequate, particularly in services of personal daily care, psychological consulting, and daily shopping.

The disparity between demand and supply of HCBS in urban and rural areas were analyzed and compared (Table 3 ). On the demand side, all of the services were higher in urban than in rural areas, except for home visits. There was a significant difference between urban and rural areas for home visits demands $(p<0.05)$. In terms of supply, we found that supply of all services in urban areas were higher than that of rural areas, except for home visits. There was a significant difference between urban and rural areas for home visits, social and recreation activities, health education, and neighboring relations services $(p<0.05)$.

\section{Factors influencing anticipated living arrangements}

Table 4 summarizes the factors influencing anticipated living arrangements. Using "living alone regardless of residential distance from children" as reference group, we discovered that predisposing variables of age and sex, enabling variables of number of children, primary caregiver, income source and need variables of loneliness, ADL all affected the anticipated living arrangements of older adults.

Results showed that older adults who were younger, male, childless and not limited in ADL have higher probability to choose "living alone regardless of residential distance from children" rather than "living alone and children living nearby" (OR=0.73, $0.81,0.18,0.67, p<0.05)$. Those who reported their primary caregiver was their son or other family members will take more concern about the residential distance from children and hope their children live nearby $(\mathrm{OR}=3.13,2.84, p<0.05)$. As for the willingness of co-residence with children, we found that respondents who were older, had more children, higher sense of loneliness and $A D L$ limitation were more willing to live with their children rather than live alone $(O R=0.56,0.28,0.54,0.63, p<0.05)$, and income source was family members will also increase the likelihood of co-residence with children $(\mathrm{OR}=1.87, p<0.05)$. Moreover, the odd ratios reaveled childless $(\mathrm{OR}=5.19, p<0.05)$ and higher sense of loneliness $(\mathrm{OR}=0.37, p<0.05)$ will significant increase the likelihood to live in institution among older adults who were living alone.

\section{Factors influencing anticipated HCBS}

As shown in Table 5, the odds ratios revealed that predisposing variables, including age, residence, and occupation, enabling resources, including income source, economic status, and availability of services, and need characteristics, including loneliness and chronic diseases had an impact on the HCBS needs of older adults.

In terms of predisposing variables, those who were younger were more likely to have demand for anticipated needs for social and recreation activities, legal aids, health education, and neighboring relations services. Urban-dwelling people tended to show needs for psychological consulting, health education, and neighboring relations services. Farmers were more in need of home visits service compared to non-farmers. For enabling variables, those who reported poor self-rated economic status and income source was family members were more likely to have various demands for HCBS compared to counterparts. Older adults who had access to personal daily care and home visits services were tend to show demands for HCBS. In the aspect of need variables, older adults with chronic diseases were more tend to have demands for personal daily care, home visits, psychological consulting and heralth education services. Furthermore, those who had higher sense of loneliness were more likely have demands for all kinds of services.

\section{Discussion}

In our study, we analyzed the demand for older adult care services and related influencing factors among older adults living alone. To the best of our knowledge, this study is the first to focus on the care needs of the solitary older adult group. The study adds to our understanding of the lives of older adults living alone and helps to raise awareness of this group.

\section{Anticipated Living Arrangements And Influencing Factors}

It is worth noting that most solitary older adults expected to continue living alone when considering their future living arrangements, with $19.2 \%$ of older adults hoping living alone regardless of residential distance with children and $56.2 \%$ hoping their children live nearby, adding up to $75.4 \%$ of all respondents. This is a 
significantly higher percentage of older adults expecting to live independently in China compared with older people in general. For instance, a comprehensive report on living arrangements of older adults showed that more than $70 \%$ older people in less developed countries co-resided with children[30]. Based on the responses to our questionnaires, we observed that the primary reason for older adults living alone was to avoid bothering their children, while secondary reasons were not having a child or their child was unable to provide care. Furthermore, nearly $50 \%$ had been living alone for over 9 years. They may have become accustomed to a solitary lifestyle, with better health and resources to live independently than those living with others[31]. Traditionally, Chinese older adults tend to rely on family members when facing difficulties[32] and their major sources of support are spouses and children, with other sources of support playing less important roles. However, the resources and levels of support may be reduced in widowed older adults[1]. In our study, $92.6 \%$ of the elderly living alone were widowed, thus, they may still prefer that their children live nearby in case instrumental and emotional support is needed. Our study indicated that co-residing with children was not the most optimal living arrangement for older adults living alone, the finding is similar to the results of Lorgan's research that the proportion of parents living with their children was reducing greatly and this pattern is being seen worldwide [33]. On the one hand, the increasing number of nuclear family pose barrier for the elderly to attain informal care, living alone may become an unavoidable choice. On the other hand, changes in social norms related to preference for co-residence may also play an important role in living independency among older adults in China. In addition, less than $3 \%$ of respondents chose institutional care, which was attributed to the psychological needs, financial status, and traditional ideas of older adults, which is consistent with previous studies[15, 34].

The results of the multinomial logistic regression revealed that age, sex, number of children, primary caregiver, income source, loneliness and ADL significantly influenced the choice of living arrangements in older adults in varying degrees.

\section{Predisposing factors}

Older adults who were younger were more likely to live alone compared with the oldest old. Health plays an important role in the ability of living alone, those younger individuals who choose to live alone tend to have better physical functioning and health than the oldest old [35], allowing them to lead an independent life. As for sex differences, women were more likely to choose "living alone and children living nearby" than men when they considering the way of living alone. It may be due to that women are located at a more vulnerable position than men in terms of economic status and requires more emotional loyalty from their family members, especially children [36], living close to children may help older adults get timely support when they are in need.

\section{Enabling factors}

We found that the more children an older adult had, the higher likelihood they chose to co-reside with children. This is greatly influenced by the concept of "filial piety" in traditional Chinese culture [37]. Taking care of parents is regarded as an obligation in traditional Chinese culture. Thus older adults who had more children were more likely to co-reside with their children to receive long-term care. With all other factors being equal, the childless older adults were more inclined to choose institutional care, which is in line with other study[38]. Because of the lack of necessary daily life care and spiritual solace, they were more willing to reside in institution in order to receive professional care services. Older adults who reported their primary caregiver were son or other family members when they were ill tended to choose the living arrangement of "living alone and children living nearby". Results showed that $49.1 \%$ of the elderly received informal care services provided by their sons. Under the influence of Confucianism, older people traditionally co-residence with one or more of their married children, usually the oldest son. However, nowadays living close to children, rather than co-residence with them, gradually become the primary living arrangement for older adults. Changes in living arrangements not signal an end to adult children's responsibility for their older parents. For older people living alone and without spouse, family members, especial their son should be their most important informal caregiver. Our study also found that older adults whose income source was family members were more likely to co-residence with children than those living support come from other sources, which was mainly basic living allowences from the government. These findings remind us more attention should be paid to the living conditions of the elederly living alone, expecially those with weak family ties and do not have access to family support.

\section{Need factors}

We found that older adults who reported that they were not limited in activities were oriented towards living alone over other living arrangements. This is similar to other study that older people who experience functional limitations often choose to live with others to obtain needed assistance when appropriate co-residents are available and willing to help[38]. Psychologically, living alone may cause the loss of interaction with family members or other social networks, and engender disappointment and depression. Feeling lonely and isolated will reinforce the desire for solitary older adults to co-reside with children to fulfill their emotional needs. This indicates that the physical and psychological condition has a significant impact on older adults' decision making regarding future living arrangements[39], and thus deserves greater attention.

\section{Anticipated Hcbs And Influencing Factors}

Our study results demonstrated that there is a mismatch between the supply and demand of HCBS, especially in personal daily care, psychological consulting, and daily shopping services. Less than $15 \%$ of respondents reported that they had access to these services in their community despite the need being over $60 \%$. Although there are increasing number of communities in China that offer an array of services for older people, we clearly showed that demand far outstrips supply. In addition, there were significant differences in HCBS provisions between urban and rural areas. These results are in line with previous studies that show that China is facing a growing gap between diversified older adult care needs and provisions, in both urban and rural areas[40]. HCBS are designed to supplement care provided by families, offering independence and choice to older adults to assist with remaining in their homes and aging in familiar environments. Studies have shed light on the importance of HCBS for buffering against hardships experienced by vulnerable older adults [41]. There are some studies demonstrated that compared with intergenerational living arrangements, those who live alone are generally more vulnerable and express a higher need for HCBS [31]. For example, a previous study found that older adults living alone were more likely to use publicly subsidized home care services to carry out instrumental activities of daily living because of the lack of informal caregivers[21]. Given the rapidly aging population and the rise in older adults 
living alone in China, developing HCBS systems is imperative. When it comes to provisions of HCBS, paying more attention to the diversity of older people and their need for different types of older adult care services is vital. Furthermore, the needs of older adults living alone should be prioritized to counteract their lack of family care resources. "Age-friendly communities" could be established, which incorporate suitable physical environments, such as housing, transportation services, and home modification programs. This would create a supportive social environment that promotes positive social relations for older residents, especially in those living alone[42]. Last but not least, additional resources should be reallocated to rural areas in order to increase older adult care services coverage, which will aid the serious imbalance between the demand for HCBS and the limited resources.

Influencing factors related to HCBS were analyzed based on the framework of Andersen's Model. Our results indicated that the anticipated HCBS of the elderly is affected by various factors.

\section{Predisposing factors}

Older adults who were younger tended to have a higher demand for social and recreation activities, legal aids, health education, and neighboring relations services than those who were older. One reason may be that they have better health and functional abilities than the oldest old and therefore have more social participation and stronger connections with neighbors. The older adults who live in urban areas are more likely to utilize psychological consulting, health education, and neighboring relations services. This could be attributed to the greater importance attached to safeguarding their health and rights than those who live in rural areas. Older adults who were engaged in agriculture were more willing to use home visit services, which is similar to the findings of other studies[40]. This is probably because these individuals usually live in rural areas where there is a higher risk of caregiver shortage due to the substantial emigration of adult children compared with urban areas[43]. Furthermore, it is more difficult in rural areas to obtain quality medical services because of resource constraints.

\section{Enabling factors}

We found that older adults who reported their income source was family members and had poor economic status were more likely to show need for HCBS. These older adults may be more economically dependent and are more likely to have unmet needs because of the lack of caregivers. Some studies have demonstrated that financial challenges can pose major barriers to older adults using care services[44, 45] and therefore, policy on income support should be introduced to enhance the older adult's purchasing power for HCBS, such as improve the subsidy mechanism of HCBS and provide some financial support for the elderly, especially those with lower income and living alone. The accessibility of HCBS also greatly influences an individual's decision to use services. For example, people who had access to personal daily care and home visit services within their community were more likely to have demand for these services. It may be that older adults who have access to HCBS have more knowledge and better understanding of these services and are thus more receptive. At present, HCBS are still in a developmental phase, which calls for continuous exploration and improvement. Greater publicity efforts are warranted to ensure awareness of available social services for the older adult community, which will promote utilization of services.

\section{Need factors}

Our study revealed that chronic diseases and the frequency of feeling lonely and isolated were significantly associated with the need for HCBS. Home visit and health education services should be given priority for the development of HCBS, and ensure to meet the older adult's health care demands. Previous studies indicated that elderly people who were socially isolated were at greater risk of experiencing poor health outcomes[46], while feelings of loneliness were positively associated with the risk of having unmet care needs[47,48]. Loneliness is believed to be a common and serious problem for the older adult population[49]. This prompts us to have more concern for the psychological status of older people living alone and more emphasis should be placed on mental health services. Taking actions such as promote solitary individuals to participate in social activities and regularly organize volunteers to visit older adults would be benefit to strengthen the connection between the elderly and society and help to reduce levels of loneliness.

The above findings illustrate that the influencing factors related to HCBS are intricate. Social workers should pay more attention to the diversity of older people and their different needs. Interventions to improve health status, relieve loneliness, increase social support, and maintain or improve the QoL of older people living alone need to be further developed and implemented.

\section{Limitations}

Several limitations to this study deserve to be mentioned. First, our data were cross-sectional, where the information collected only reflected the demand for older adult care services in 2018 (only one wave of the CLHLS) and therefore causal conclusions cannot be made. If all waves of the survey are eventually analyzed, it will be possible to observe the demand for older adult care services temporally. Second, there were some deficiencies in the adopted indicators. For instance, the frequency of feeling loneliness was applied to describe psychological status, which is a subjective indicator and thus may lead to some bias. Since older adult health is multi-dimensional, a well-rounded evaluation of health status would require a combination of subjective and objective indicators. Third, in our study, HCBS were grouped into eight general categories. However, details about demands for HCBS such as refined items, amount, and frequency of services maybe important for a deeper understanding of older adult's demand but they were not able to be adopted in analysis due to relevant information were not provided by CLHLS database. Even with these limitations, this research still contribute to enrich the study of older adults living alone. For one thing, it provided fresh information about the willingness of future living arrangements among the older adults living alone and described the supply-demand of present HCBS in China. The results suggested that more efforts should be made to enrich the content of HCBS. For another, it explored the influencing factors of older adults care needs, which enables policymakers understand the determinants of the older adult's demands for HCBS and make proper decisions to enhance the efficiency of HCBS provisions.

\section{Conclusions}


In conclusion, the majority of solitary older adults hope to maintain living alone when considering future living arrangements. There is a high demand for HCBS among older adults living alone. However, the social services provided by communities are not sufficient to satisfy the needs of the older people both in urban and rural areas. The government should take action towards developing HCBS and creating a supportive environment for older adults living alone. Moreover, health care and psychological consulting services should be prioritized, and access guaranteed in all communities.

Furthermore, based on the Andersen model, our study found that older adult care needs can be influenced by predisposing factors (age, sex, residence, and occupation), enabling resources (number of children, primary caregiver, income source, economic status and availability of services) and need variables (loneliness, ADL, and chronic diseases). HCBS should be provided according to the needs of older adults with consideration of their differing characteristics.

\section{List Of Abbreviations}

CLHLS

Chinese Longitudinal Healthy Longevity Survey; HCBS:home and community-based care services; ADL:activities of daily living; QoL:quality of life.

\section{Declarations}

\section{Ethics approval and consent to participate}

The Chinese Longitudinal Healthy Longevity Survey (CLHLS) was approved by the Institutional Review Board, Duke University (Pro00062871), and the Biomedical Ethics Committee, Peking University(IRB00001052-13074). Permissions are required to access the raw data from the CLHLS. This study obtained the CLHLS data by submitting a data use agreement, which was approved by Zheng Zhenzhen, Executive Associate Director of Center for Healthy Aging and Familiy Studies, Peking University.

\section{Consent for publication}

Not applicable.

\section{Availability of data and material}

The analytical datast used in this study is a publicly available dataset released by the CLHLS. Information about the data source and available data are found at https://www.icpsr.umich.edu/web/DSDR/studies/36179. Researchers can ovtain these data after submitting a data use agreement to the CLHLS team.

\section{Competing interests}

The authors declare that they have no competing interests.

\section{Funding}

This work was supported by the National Natural Science Foundation of China [grant number $81973144 \& 71874147$ ]. The funders had no role in the study design, data collection and analysis, decision to publish or preparation of the manuscript.

\section{Author contributions}

YF conceived and designed the study, supervised the data analysis; YBZ and CXL wrote the paper; YBZ performed all statistical analyses and CXL contributed to revising the paper. All authors read and approved the final manuscript.

\section{Acknowledgments}

The authors would like to thank the Center for Healthy Aging and Development Studies, Peking University for supporting this database. Data used for this research was provided by the study entitled 'Chinese Longitudinal Healthy Longevity Survey' (CLHLS) managed by the Center for Healthy Aging and Development Studies, Peking University. CLHLS is supported by funds from the U.S. National Institutes on Aging (NIA), China Natural Science Foundation, China Social Science Foundation, and UNFPA.

\section{References}

1. Chen Y, While AE: Older people living alone in Shanghai: A questionnaire survey of their life experience. Health Soc Care Community 2019, 27(1):260-269.

2. United Nations Department of Economic and Social Affairs: World Population Prospects: The 2010 Revision. New York: United Nations 2011.

3. Ren Q, Treiman DJ: Living Arrangements of the Elderly in China and Consequences for Their Emotional Well-being. Chinese Sociological Review 2015, 47(3):255-286

4. Chen T, Leeson GW, Liu C: Living arrangements and intergenerational monetary transfers of older Chinese. Ageing and Society 2016, 37(9):1798-1823.

5. Chen Y, Hicks A, While AE: Loneliness and social support of older people living alone in a county of Shanghai, China. Health Soc Care Community 2014, 22(4):429-438.

6. WHO: Prevention of Mental Disorders in the Elderly. Copenhagen: World Health Organization 1977.

7. Cheng ST, Fung HH, Chan AC: Living status and psychological well-being: social comparison as a moderator in later life. Aging Ment Health 2008, 12(5):654-661. 
8. Ye M, Chen Y: The influence of domestic living arrangement and neighborhood identity on mental health among urban Chinese elders. Aging Ment Health 2014, 18(1):40-50.

9. Cheng ST, Lee CK, Chan AC, Leung EM, Lee JJ: Social network types and subjective well-being in Chinese older adults. J Gerontol B Psychol Sci Soc Sci 2009, 64(6):713-722.

10. Zhai Y, Yi H, Shen W, Xiao Y, Fan H, He F, Li F, Wang X, Shang X, Lin J: Association of empty nest with depressive symptom in a Chinese elderly population: A cross-sectional study. J Affect Disord 2015, 187:218-223.

11. Chou KL, Ho AH, Chi I: Living alone and depression in Chinese older adults. Aging Ment Health 2006, 10(6):583-591.

12. Mao X, Han W-J: Living Arrangements and Older Adults' Psychological Well-Being and Life Satisfaction in China: Does Social Support Matter? Family Relations 2018, 67(4):567-584.

13. Michael YL, Berkman, L. F., Colditz, G. A., Kawachi, I: Living anrangements, social integration, and change in functional health status. American Journal of Epidemiology 2001, 153:123-131.

14. Turner AJ, Nikolova S, Sutton M: The effect of living alone on the costs and benefits of surgery amongst older people. Soc Sci Med 2016, $150: 95-103$.

15. Kim H-J, Hong S, Kim M: Living Arrangement, Social Connectedness, and Life Satisfaction among Korean Older Adults with Physical Disabilities: The Results from the National Survey on Persons with Disabilities. Journal of Developmental and Physical Disabilities 2014, 27(3):307-321.

16. Li LW, Zhang J, Liang J: Health among the oldest-old in China: which living arrangements make a difference? Soc Sci Med 2009, 68(2):220-227.

17. Feinian Chen S, S. E. : Household context and subjective well-being among the oldest old in China. Journal of Family Issues 2008, 29(10):1379-1403.

18. Zhang NJ, Guo M, Zheng X: China: awakening giant developing solutions to population aging. Gerontologist 2012, 52(5):589-596.

19. Weaver RH, Roberto KA: Home and Community-Based Service Use by Vulnerable Older Adults. Gerontologist 2017, 57(3):540-551.

20. Howell S, Silberberg, M., Quinn, W. V., \& Lucas, J. A: Determinants of remaining in the community after discharge: Results from New Jersey's Nursing Home Transition Program. The Gerontologist 2007, 47(4):535-547.

21. Lau DT, Kirby JB: The relationship between living arrangement and preventive care use among community-dwelling elderly persons. Am J Public Health 2009, 99(7):1315-1321.

22. Su D, Wu XN, Zhang YX, Li HP, Wang WL, Zhang JP, Zhou LS: Depression and social support between China' rural and urban empty-nest elderly. Arch Gerontol Geriatr 2012, 55(3):564-569.

23. Chen T: Living arrangement preferences and realities for elderly Chinese: implications for subjective wellbeing. Ageing and Society 2018, 39(8):15571581.

24. Ning Liu LZ, Zhe Li and Jue Wang: Health-related quality of life and long-term care needs among elderly individuals living alone: a cross-sectional study in rural areas of Shaanxi Province, China. Bmc Public Health 2013, 13:313.

25. Zeng Y, Feng Q, Gu D, Vaupel JW: Demographics, phenotypic health characteristics and genetic analysis of centenarians in China. Mech Ageing Dev 2017, 165(Pt B):86-97.

26. Andersen R: National health surveys and the Behavioral Model of Health Services Use. Med Care 2008, 46(7):7.

27. Zeng L, Xu X, Zhang C, Chen L: Factors Influencing Long-Term Care Service Needs among the Elderly Based on the Latest Anderson Model: A Case Study from the Middle and Upper Reaches of the Yangtze River. Healthcare (Basel) 2019, 7(4).

28. Ferris RE, Glicksman A, Kleban MH: Environmental Predictors of Unmet Home-and Community-Based Service Needs of Older Adults. J App/ Gerontol 2016, 35(2):179-208.

29. Hsu HC: Effects of physical function trajectories on later long-term care utilization among the Taiwanese elderly. Geriatr Gerontol Int 2013, 13(3):751-758.

30. Lee SM, Edmonston B: Living Alone Among Older Adults in Canada and the U.S. Healthcare (Basel) 2019, 7(2).

31. Xu Q, Norstrand JA, Du Y: Effects of Living Alone on Social Capital and Health Among Older Adults in China. Int J Aging Hum Dev 2015, 82(1):30-53.

32. Mui AC, Glajchen M, Chen H, Sun J: Developing an Older Adult Volunteer Program in a New York Chinese Community: An Evidence-Based Approach. Ageing Int 2013, 38(2):108-121.

33. Logan J, Bian FQ, Bian YJ: Tradition and change in the urban Chinese family: The case of living arrangements. Social Forces 1998, Vol. 76, No. 3 (Mar., 1998).

34. Sereny M: Living Arrangements of Older Adults in China: The Interplay Among Preferences, Realities, and Health. Res Aging 2011, 33(2):172-204.

35. Yang W-S, Shih Y-C, Li Y-T: Living arrangements, coresidence preference, and mortality risk among older Taiwanese. Asian Education and Development Studies 2017, 6(2):192-204.

36. Yount KM, Khadr Z: Gender, Social Change, and Living Arrangements Among Older Egyptians During the 1990s. Population Research and Policy Review 2008, 27(2):201-225.

37. Zhang L, Zeng Y, Fang Y: The effect of health status and living arrangements on long term care models among older Chinese: A cross-sectional study. Plos One 2017, 12(9):e0182219.

38. Burr JA, Mutchler JE: Residential independence among older persons: community and individual factors. Population Research and Policy Review 2007, 26(1):85-101.

39. Lai D, Tong H, Zeng Q, Xu W: The factor structure of a Chinese Geriatric Depression Scale-SF: use with alone elderly Chinese in Shanghai, China. Int J Geriatr Psychiatry 2010, 25(5):503-510.

40. Zhou J, Walker, A. : The need for community care among older people in China. Ageing \& Society 2016, 36(6):1312-1332. 
41. Chen Q, Amano T, Park S, Kim B: Home and Community-based Services and Life Satisfaction among Homebound and Poor Older Adults. J Gerontol Soc Work 2019, 62(7):708-727.

42. Lui CW, Everingham JA, Warburton J, Cuthill M, Bartlett $\mathrm{H}$ : What makes a community age-friendly: A review of international literature. Australas J Ageing 2009, 28(3):116-121.

43. Feng Z, Liu C, Guan X, Mor V: China's rapidly aging population creates policy challenges in shaping a viable long-term care system. Health Aff (Millwood) 2012, 31(12):2764-2773.

44. Chen L, Zhang X, Xu X: Health Insurance and Long-Term Care Services for the Disabled Elderly in China: Based on CHARLS Data. Risk Manag Healthc Policy 2020, 13:155-162.

45. Valaitis R, Cleghorn L, Ploeg J, Risdon C, Mangin D, Dolovich L, Agarwal G, Oliver D, Gaber J, Chung H: Disconnected relationships between primary care and community-based health and social services and system navigation for older adults: a qualitative descriptive study. Bmc Fam Pract 2020,21 (1):69.

46. Lee JMG, Chan CQH, Low WC, Lee KH, Low LL: Health-seeking behaviour of the elderly living alone in an urbanised low-income community in Singapore. Singapore Med J 2019.

47. Burchardt T, Jones E, Obolenskaya P: Formal and Informal Long-Term Care in the Community: Interlocking or Incoherent Systems? Journal of Social Policy 2018, 47(3):479-503.

48. Andrade TB, Andrade FB: Unmet need for assistance with activities of daily life among older adults in Brazil. Rev Saude Publica 2018, 52:75.

49. Heylen L: The older, the lonelier? Risk factors for social loneliness in old age. Ageing Soc 2010, 30(7):1177-1196.

\section{Tables}


Table 1

Simple descriptive statistics of the sample $(N=2217)$

\begin{tabular}{|c|c|c|c|}
\hline Variables & Groups & Participants & Percent (\%) \\
\hline \multicolumn{4}{|l|}{ Predisposing variables } \\
\hline \multirow[t]{3}{*}{ Age } & $65-74$ & 296 & 13.4 \\
\hline & $75-84$ & 739 & 33.3 \\
\hline & $\geq 85$ & 1182 & 53.3 \\
\hline \multirow[t]{2}{*}{ Sex } & Male & 800 & 36.1 \\
\hline & Female & 1417 & 63.9 \\
\hline \multirow[t]{2}{*}{ Residence } & Rural & 1092 & 49.3 \\
\hline & Urban & 1125 & 50.7 \\
\hline \multirow[t]{2}{*}{ Occupation } & Farmer & 1541 & 69.5 \\
\hline & Non-farmer & 676 & 30.5 \\
\hline \multirow[t]{3}{*}{ Years of schooling } & 0 & 1279 & 57.7 \\
\hline & $1-6$ & 654 & 29.7 \\
\hline & $\geq 7$ & 284 & 12.8 \\
\hline \multicolumn{4}{|l|}{ Enabling variables } \\
\hline \multirow[t]{4}{*}{ Marriage status } & In marriage & 75 & 3.4 \\
\hline & Divorced & 20 & 0.9 \\
\hline & Widowed & 2054 & 92.6 \\
\hline & Never married & 68 & 3.1 \\
\hline \multirow[t]{3}{*}{ Number of children } & 0 & 118 & 5.3 \\
\hline & $1-3$ & 683 & 30.8 \\
\hline & $\geq 4$ & 1416 & 63.9 \\
\hline \multirow[t]{4}{*}{ Primary caregiver } & Son & 1089 & 49.1 \\
\hline & Other relatives & 896 & 40.5 \\
\hline & Friends & 91 & 4.1 \\
\hline & Nobody & 141 & 6.4 \\
\hline \multirow[t]{3}{*}{ Economic status } & High & 306 & 13.8 \\
\hline & Intermediate & 1568 & 70.7 \\
\hline & Low & 343 & 15.5 \\
\hline \multirow[t]{3}{*}{ Income source } & Self & 593 & 26.7 \\
\hline & Family members & 1081 & 48.8 \\
\hline & Others & 543 & 24.5 \\
\hline \multicolumn{4}{|l|}{ Need variables } \\
\hline \multirow[t]{2}{*}{ ADL } & Not limited & 1508 & 68.0 \\
\hline & Limited & 709 & 32.0 \\
\hline \multirow[t]{3}{*}{ Self-rated health } & Good & 998 & 45.0 \\
\hline & Fair & 885 & 39.9 \\
\hline & Bad & 334 & 15.1 \\
\hline \multirow[t]{3}{*}{ Feel lonely and isolated } & Never & 1200 & 54.1 \\
\hline & Sometimes & 667 & 30.1 \\
\hline & Always & 350 & 15.8 \\
\hline Number of chronic diseases & 0 & 680 & 30.7 \\
\hline
\end{tabular}

Page 10/13 


\begin{tabular}{|llll|}
\hline Variables & Groups & Participants & Percent (\%) \\
\hline 1 & 702 & 31.7 \\
& $\geq 2$ & 835 & 37.6 \\
\hline
\end{tabular}

Table 2. Anticipated living arrangements of elderly subjects living alone with different characteristics

\begin{tabular}{|c|c|c|c|c|c|c|c|}
\hline Variables & Group & Living alone $^{1}(\%)$ & $\begin{array}{l}\text { Living alone }{ }^{2} \\
\text { (\%) }\end{array}$ & $\begin{array}{l}\text { Co-residence } \\
\text { with children } \\
\text { (\%) }\end{array}$ & $\begin{array}{l}\text { Institutions } \\
\text { (\%) }\end{array}$ & $\begin{array}{l}\text { Don't know } \\
\text { (\%) }\end{array}$ & $x^{2}$ \\
\hline Overall & & 19.2 & 56.2 & 17.2 & 2.1 & 5.3 & \\
\hline \multirow[t]{3}{*}{ Age } & $65-74$ & 22.6 & 52.4 & 18.6 & 3.7 & 2.7 & $46.708^{\star \star \star}$ \\
\hline & $75-84$ & 23.4 & 57.8 & 13.7 & 1.8 & 3.4 & \\
\hline & $\geq 85$ & 15.7 & 56.1 & 19.1 & 1.9 & 7.2 & \\
\hline \multirow[t]{2}{*}{ Sex } & Male & 22.0 & 52.9 & 16.9 & 3.5 & 4.8 & $19.736^{\star \star \star}$ \\
\hline & Female & 17.6 & 58.0 & 17.4 & 1.3 & 5.6 & \\
\hline \multirow[t]{2}{*}{ Residence } & Rural & 17.9 & 56.9 & 17.0 & 2.2 & 6.0 & 3.583 \\
\hline & Urban & 20.4 & 55.5 & 17.4 & 2.0 & 4.7 & \\
\hline \multirow[t]{3}{*}{ Years of schooling } & 0 & 17.0 & 56.0 & 18.4 & 2.3 & 68.6 & $20.857 * *$ \\
\hline & $1-7$ & 20.9 & 56.3 & 17.1 & 2.1 & 19.5 & \\
\hline & $>7$ & 24.6 & 56.7 & 12.3 & 1.4 & 11.9 & \\
\hline \multirow[t]{3}{*}{ Number of children } & 0 & 34.7 & 16.1 & 8.5 & 17.8 & 22.9 & 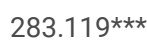 \\
\hline & $1-3$ & 21.4 & 55.2 & 17.7 & 1.9 & 3.8 & \\
\hline & $\geq 4$ & 16.8 & 60.0 & 17.7 & 0.9 & 4.6 & \\
\hline \multirow[t]{3}{*}{ Economic status } & High & 23.2 & 62.1 & 11.1 & 1.3 & 2.3 & $70.470 * * *$ \\
\hline & Intermediate & 18.2 & 57.9 & 17.5 & 1.7 & 4.7 & \\
\hline & Low & 19.8 & 42.9 & 21.3 & 5.0 & 11.1 & \\
\hline \multirow[t]{3}{*}{ Income source } & Self & 23.6 & 58.5 & 12.1 & 2.5 & 3.2 & $64.468 * \star \star$ \\
\hline & Family members & 15.1 & 57.3 & 21.1 & 1.0 & 5.6 & \\
\hline & Others & 22.5 & 51.4 & 15.1 & 3.9 & 7.2 & \\
\hline \multirow[t]{4}{*}{ Primary caregiver } & Son & 16.4 & 61.7 & 17.0 & 0.8 & 4.1 & $173.942^{\star \star \star}$ \\
\hline & Other relatives & 18.7 & 57.0 & 16.3 & 1.9 & 6.1 & \\
\hline & Friends & 25.8 & 23.6 & 22.5 & 15.7 & 12.4 & \\
\hline & Nobody & 36.0 & 31.7 & 22.3 & 5.0 & 5.0 & \\
\hline \multirow[t]{3}{*}{ Feel lonely and isolated } & Never & 20.0 & 58.3 & 15.1 & 1.4 & 5.2 & $47.046 * \star \star$ \\
\hline & Sometimes & 19.5 & 57.6 & 16.3 & 2.1 & 4.5 & \\
\hline & Always & 15.7 & 46.0 & 26.3 & 4.6 & 7.4 & \\
\hline \multirow[t]{3}{*}{ Self-rated health } & Good & 20.6 & 59.7 & 13.3 & 1.4 & 4.9 & $42.461^{\star \star \star}$ \\
\hline & Fair & 18.1 & 55.9 & 18.5 & 2.3 & 5.2 & \\
\hline & Bad & 17.7 & 46.1 & 25.4 & 3.9 & 6.9 & \\
\hline \multirow[t]{2}{*}{$A D L$} & Not limited & 21.8 & 56.7 & 15.8 & 1.8 & 3.8 & $44.429 * \star *$ \\
\hline & Limited & 13.5 & 55.0 & 20.2 & 2.8 & 8.5 & \\
\hline
\end{tabular}

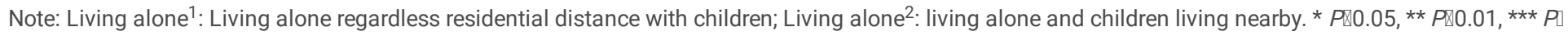
0.001 .

Table 3. Comparative analysis of the demand and actual supply in urban and rural areas 


\begin{tabular}{|llllllllll|}
\hline Social services & \multicolumn{7}{l}{ Demand(\%) } & \multicolumn{7}{l|}{ Supply(\%) } \\
& Overall & Urban & Rural & $X^{2}$ & Overall & Urban & Rural & $X^{2}$ \\
\hline Personal daily care & 65.69 & 66.25 & 65.10 & 0.300 & 9.06 & 9.87 & 8.28 & 1.549 \\
\hline Home visits & 81.73 & 79.89 & 83.65 & $4.863^{*}$ & 31.63 & 29.47 & 34.03 & $4.908^{*}$ \\
\hline Psychological consulting & 70.18 & 71.40 & 68.89 & 1.541 & 13.99 & 14.37 & 13.67 & 0.205 \\
\hline Daily shopping & 62.13 & 62.25 & 62.01 & 0.012 & 11.10 & 10.82 & 10.78 & 0.001 \\
\hline Social and recreation activities & 67.39 & 68.06 & 66.70 & 0.435 & 19.39 & 22.20 & 17.37 & $7.523^{*}$ \\
\hline Legal aids & 65.25 & 66.35 & 64.10 & 1.136 & 19.58 & 21.57 & 18.26 & 3.504 \\
\hline Health education & 73.63 & 75.50 & 71.68 & 3.845 & 37.40 & 40.00 & 35.23 & $4.958^{*}$ \\
\hline Neighboring relations & 67.74 & 68.83 & 66.60 & 1.164 & 28.73 & 32.34 & 25.75 & $10.783^{\star *}$ \\
\hline
\end{tabular}

Note: * $P \otimes 0.05, * \star P \otimes 0.01, * * * P \otimes 0.001$.

Table 4. Multinomial logistic regression results of anticipated living arrangements

\begin{tabular}{|c|c|c|c|c|c|c|c|}
\hline \multirow[t]{2}{*}{ Variables } & \multirow[t]{2}{*}{ Refer } & \multicolumn{2}{|c|}{ Living alone $^{2}$} & \multicolumn{2}{|c|}{ Co-residence with children } & \multicolumn{2}{|c|}{ Institutions } \\
\hline & & $\beta$ & $O R$ & $\beta$ & $O R$ & $\beta$ & $O R$ \\
\hline \multicolumn{8}{|l|}{ Predisposing variables } \\
\hline Age & $\geq 85$ & & & & & & \\
\hline $65-74$ & & -0.12 & 0.89 & -0.03 & 1.03 & 0.42 & 1.52 \\
\hline $75-84$ & & -0.31 & $0.73^{\star}$ & -0.58 & $0.56^{\star \star}$ & -0.17 & 0.84 \\
\hline Sex & Female & -0.21 & $0.81 *$ & -0.12 & 0.89 & 0.24 & 1.28 \\
\hline \multicolumn{8}{|l|}{ Enabling variables } \\
\hline \multicolumn{8}{|l|}{ Number of children } \\
\hline 0 & $\geq 4$ & -1.71 & $0.18^{\star \star \star}$ & -1.29 & $0.28 * *$ & 1.65 & $5.19 * *$ \\
\hline $1-3$ & & -0.10 & 0.90 & 0.04 & 1.04 & 0.36 & 1.43 \\
\hline Primary caregiver & Nobody & & & & & & \\
\hline Son & & 1.14 & $3.13^{* \star *}$ & 0.29 & 1.33 & -0.25 & 0.78 \\
\hline Other relatives & & 1.04 & $2.84^{\star \star \star}$ & 0.21 & 1.24 & 0.05 & 1.06 \\
\hline Friends & & -0.13 & 0.88 & 0.37 & 1.44 & 1.79 & $1.80 * *$ \\
\hline Income Source & Others & & & & & & \\
\hline Self & & 0.09 & 1.10 & -0.09 & 0.92 & 0.20 & 1.22 \\
\hline Family members & & 0.27 & 1.30 & 0.63 & $1.87^{\star *}$ & -0.15 & 0.86 \\
\hline \multicolumn{8}{|l|}{ Need variables } \\
\hline Feel lonely and isolated & Always & & & & & & \\
\hline Never & & -0.16 & 0.86 & -0.62 & $0.54 * \star$ & -1.01 & $0.37 *$ \\
\hline Sometimes & & -0.17 & 0.85 & -0.63 & $0.53^{\star \star}$ & -0.61 & 0.54 \\
\hline$A D L$ & limited & & & & & & \\
\hline Not limited & & -0.40 & $0.67^{\star *}$ & -0.46 & $0.63^{\star *}$ & -0.70 & 0.50 \\
\hline \multicolumn{8}{|l|}{ Model summary } \\
\hline Х2 (P-value) & $338.84(<$ & $0.001)$ & & & & & \\
\hline-2 Log likelihood & 3176.28 & & & & & & \\
\hline Nagelkerke $\mathrm{R}^{2}$ & 0.17 & & & & & & \\
\hline
\end{tabular}

Note: Taking "Living alone ${ }^{1 "}$ as a reference. Living alone ${ }^{1}$ : Living alone regardless of residential distance with children; Living alone ${ }^{2}$ : living alone and children living nearby. * $P \otimes 0.05, * \star P \otimes 0.01, * \star \star P \otimes 0.001$ 
Table 5. Binary logistic regression results of anticipated home and community-based services

\begin{tabular}{|c|c|c|c|c|c|c|c|c|c|c|c|c|c|c|c|}
\hline \multirow{2}{*}{$\begin{array}{l}\text { Variables } \\
\text { Predisposing } \\
\text { variables }\end{array}$} & \multirow[t]{2}{*}{ Refer } & \multicolumn{2}{|c|}{$\begin{array}{l}\text { Personal daily } \\
\text { care }\end{array}$} & \multicolumn{2}{|c|}{ Home visits } & \multicolumn{2}{|c|}{$\begin{array}{l}\text { Psychological } \\
\text { consulting }\end{array}$} & \multicolumn{2}{|c|}{ Daily shopping } & \multicolumn{2}{|c|}{$\begin{array}{l}\text { Social and } \\
\text { recreation } \\
\text { activities }\end{array}$} & \multicolumn{2}{|c|}{ Legal aids } & \multicolumn{2}{|c|}{$\begin{array}{l}\text { Health } \\
\text { education }\end{array}$} \\
\hline & & $B$ & $O R$ & $B$ & $O R$ & $B$ & $O R$ & $B$ & $O R$ & $B$ & $O R$ & $B$ & $O R$ & $B$ & $O R$ \\
\hline Age & $65-74$ & & & & & & & & & & & & & & \\
\hline $75-84$ & & -0.02 & 0.89 & -0.14 & 0.87 & -0.23 & 0.80 & -0.22 & 0.81 & -0.25 & 0.78 & -0.15 & $0.87 \star \star$ & -0.38 & $0.68^{*}$ \\
\hline$\geq 85$ & & 0.06 & 1.06 & 0.12 & 1.13 & -0.02 & 0.98 & -0.25 & 0.78 & -0.39 & $0.68^{*}$ & -0.21 & 0.82 & -0.45 & $0.64^{\star \star}$ \\
\hline Residence & Rural & 0.17 & 1.19 & 0.04 & 1.04 & 0.21 & $1.25^{\star}$ & 0.09 & 1.09 & 0.70 & 1.07 & 0.14 & 1.15 & 0.35 & $1.43^{* *}$ \\
\hline Occupation & $\begin{array}{l}\text { Non- } \\
\text { farmer }\end{array}$ & 0.16 & 1.17 & 0.42 & $1.53^{\star \star}$ & 0.02 & 1.02 & -0.05 & 0.95 & -0.08 & 0.92 & -0.06 & 0.94 & 0.15 & 1.16 \\
\hline \multicolumn{16}{|l|}{$\begin{array}{l}\text { Enabling } \\
\text { variables }\end{array}$} \\
\hline $\begin{array}{l}\text { Income } \\
\text { source }\end{array}$ & Self & & & & & & & & & & & & & & \\
\hline $\begin{array}{l}\text { Family } \\
\text { members }\end{array}$ & & 0.27 & $1.31 *$ & 0.54 & $1.72^{\star \star \star}$ & 0.18 & 1.20 & 0.35 & $1.42^{\star \star}$ & 0.21 & 1.24 & 0.15 & 1.17 & 0.34 & $1.41^{\star}$ \\
\hline Others & & 0.04 & 1.05 & 0.13 & 1.14 & 0.12 & 1.13 & 0.17 & 1.19 & 1.51 & 1.16 & 0.15 & 1.16 & 0.32 & $1.38^{*}$ \\
\hline $\begin{array}{l}\text { Economic } \\
\text { status }\end{array}$ & High & & & & & & & & & & & & & & \\
\hline Intermediate & & 0.12 & 1.13 & 0.04 & 1.04 & 0.05 & 1.06 & 0.08 & 1.08 & -0.21 & 1.24 & 0.15 & 1.17 & 0.09 & 1.09 \\
\hline Low & & 0.44 & $1.56^{\star}$ & 0.34 & 1.41 & 0.27 & 1.31 & 0.40 & $1.50 *$ & 0.15 & 1.16 & 0.23 & 1.25 & 0.18 & 1.19 \\
\hline $\begin{array}{l}\text { Availability } \\
\text { of personal } \\
\text { daily care } \\
\text { services }\end{array}$ & No & 1.44 & 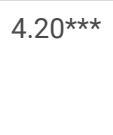 & 0.41 & 1.51 & 0.87 & $2.38^{\star \star \star}$ & 0.98 & $2.66^{\star \star \star}$ & 0.74 & $2.09 \star \star \star$ & 0.81 & $2.25^{\star \star \star}$ & 0.62 & $1.87^{\star *}$ \\
\hline $\begin{array}{l}\text { Availability } \\
\text { of home } \\
\text { visits } \\
\text { services }\end{array}$ & No & 0.07 & 1.08 & 1.23 & 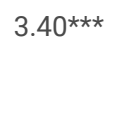 & 0.49 & $1.65^{\star \star \star}$ & 0.13 & 1.14 & 0.38 & $1.46^{\star \star \star}$ & 0.25 & $1.28^{*}$ & 0.57 & $1.77^{\star \star}$ \\
\hline \multicolumn{16}{|l|}{$\begin{array}{l}\text { Need } \\
\text { variables }\end{array}$} \\
\hline $\begin{array}{l}\text { Feel lonely } \\
\text { and isolated }\end{array}$ & Never & & & & & & & & & & & & & & \\
\hline \multicolumn{2}{|l|}{ Sometimes } & 0.26 & $1.30 *$ & 0.51 & 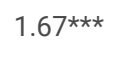 & 0.25 & $1.28^{*}$ & 0.27 & $1.30 * \star$ & 0.24 & 1.27 & 0.25 & $1.28^{*}$ & 0.23 & $1.23^{*}$ \\
\hline Always & & 0.50 & $1.65^{\star \star}$ & 0.34 & $1.41^{*}$ & 0.48 & $1.61^{\star \star}$ & 0.40 & $1.50 * \star$ & 0.36 & $1.46^{*}$ & 0.39 & $1.47 \star \star$ & 0.21 & 1.30 \\
\hline $\begin{array}{l}\text { Have chronic } \\
\text { diseases }\end{array}$ & No & 0.20 & $1.22^{\star}$ & 0.43 & $1.54^{\star \star}$ & 0.25 & $1.29 *$ & 0.19 & 1.21 & 0.12 & 1.13 & 0.18 & 1.19 & 0.26 & $1.30 *$ \\
\hline \multicolumn{16}{|l|}{$\begin{array}{l}\text { Model } \\
\text { summary }\end{array}$} \\
\hline $\begin{array}{l}\chi 2(P- \\
\text { value })\end{array}$ & & \multicolumn{2}{|c|}{$98.14(<0.001)$} & \multicolumn{2}{|c|}{$\begin{array}{l}163.99 \\
(<0.001)\end{array}$} & \multicolumn{2}{|c|}{$80.06(0.001)$} & \multicolumn{2}{|c|}{$71.71(<0.001)$} & \multicolumn{2}{|c|}{$57.24(<0.001)$} & \multicolumn{2}{|c|}{$55.01(<0.001)$} & \multicolumn{2}{|c|}{$79.79(<0.001)$} \\
\hline \multicolumn{2}{|c|}{$\begin{array}{l}\text { Percentange of } \\
\text { correct prediction }\end{array}$} & \multicolumn{2}{|c|}{$76.26 \%$} & \multicolumn{2}{|c|}{$81.91 \%$} & \multicolumn{2}{|c|}{$70.18 \%$} & \multicolumn{2}{|c|}{$72.20 \%$} & \multicolumn{2}{|c|}{$77.21 \%$} & \multicolumn{2}{|c|}{$75.58 \%$} & \multicolumn{2}{|c|}{$73.74 \%$} \\
\hline
\end{tabular}

Note: The table presents the final results when all sets of variables were entered at once, for the sake of presentational simplification. * $P ख 0.05$, $* \star P ख 0.01, \star \star \star ~ P$ $₫ 0.001$. 